\title{
Research on Road Performance of Chemical Modified Nanning Expansive Soil
}

\author{
Tang Xian-yuan ${ }^{1,2, a}$, Yang He-ping ${ }^{1, b}$ Li Ying-chun $^{3, c}$ \\ 1. Key Laboratory of road structure and material transportation industry, Changsha University of \\ Science and Technology, Hunan Changsha, 410076; \\ 2. School of civil engineering and architecture, Guangxi science and Technology University, \\ Guangxi Liuzhou, 545006; \\ 3. Transportation planning survey and design institute of Guangxi, Guangxi Nanning, 530011 \\ a thy1188@126.com, ${ }^{b}$ cscuyang@163.com, ${ }^{\mathrm{c}}$ lyc2663@163.com
}

Keywords: expansive soil, chemical improvement; lime; cement; fly ash

Abstract. To study on the chemical effects on Nanning expansive soils the lime, cement and fly ash were utilized as modifier to treat three different kinds of expansive soil. The fundamental engineering properties of expansive soil were analyzed to evaluate the improved effects and adaptability. The results indicate that it is significant to increase the strength of expansive soil and reduce the swelling-shrinkage properties with the addition of lime; with 5-7\% addition of lime, the CBR values and total rate of swelling-shrinkage can be great and less than $3 \%$ and $0.7 \%$, respectively. All can meet the specification requirement. The addition of cement increase the strength of expansive soil considerably, but reduce the total rate of swelling-shrinkage poorly. It is not significant to increase the CBR values with the addition of fly ash.

\section{Foreword}

It has great harm to highway construction because of the obvious swelling shrinkage, over consolidation and multi-cracks of expansive soil. The provisions of the existing specifications for highway expansive soil should not be directly used for filling of subgrade before the corresponding treatment. Chemically modified engineering Treatment is commonly used measures of expansive soil, Chemical materials commonly used in highway engineering are: lime, fly ash, cement, chemical stability, etc. ${ }^{[1]}$.

Lime improvement can significantly improve the working performance of expansive soil. In recent 10 years, at home and abroad, the research of lime improved expansive soil mainly concentrates on the determination of control index, such as the optimal lime ratio, degree of compaction, moisture content and curing time control indexes determined, as well as the construction technology and its quality control and assessment ${ }^{[2-3]}$. Cement and fly ash are commonly used expansive soil improvement materials, the research mainly concentrates on the improvement effect and the best dosage of cement or fly ash to expansive soil ${ }^{[4-5]}$; At the same time, the comprehensive improvement method of many materials also has some research, such as lime and fly ash, cement, gravel, and other comprehensive modification of geotechnical materials ${ }^{[6-7]}$.

But most of the research above is focused on the improvement of the strength and shrinkage of the expansive soil, and less attention is focused on the effect of different materials on the road performance of expansive soil. In the expansion of land area, in fact, highway construction has the characteristics of long route, large quantity and complicated soil complexity, and the selection of the material for improvement must pay attention to the improvement of the road performance. According to the current specifications to determine to CBR strength and swelling shrinkage rate as the main performance index, in this paper, the expansive soil of three kinds of different sections in Nanning outer ring road is selected as the object, and three kinds of modified materials, such as lime, cement and fly ash, are selected for improvement. It provides a reference for the practice of subgrade filling in the expansive soil area. 


\section{Cause and basic properties of expansive soil in Nanning outer ring road}

In the construction of Nanning outer ring highway with a length of about $79 \mathrm{~km}$, of which $\mathrm{K} 6+000 \sim \mathrm{K} 29+700$ is a typical expansive soil distribution in Nanning basin., and the expansive soil subgrade cut up to 250 million cubic meters, with the roadbed fill about 320 million cubic meters. As it is located in the suburbs of Nanning, the project has a high requirements on the conservation of land, environment and landscape. If the excavation Subgrade of expansive soil are abandoned, it will need to occupy large areas of land, which will bring great damage of the ecological environment along the highway; however, the embankment must be filled with the earth from a long distance, in which case, large investment and long construction period is needed. Therefore, in order to put forward the feasible and economical method of expansive soil filling, and for the reasonable use of expansive soil and provide evidence of subgrade treatment design, we must carry out the experimental study on treatment technology of expansive soil embankment using

The geological drilling results show that the expansive soil distribution area of the Nanning outer ring road is mainly composed of the mudstone, silty mudstone and its weathering layer of the upper part (N 23). In this area, the bedrock weathering degree is high, and the rock is very soft. The lower layer is weak medium weathered and expanded shale, and the color is gunmetal-gray. In case of water, it is extremely easy to collapse, expand and collapse, and to form a large number of cracks after air-drying; The upper layer is strong completely weathering layer, which color is similar to the earthy yellow, gray and grayish green; Covering layer is different with the Quaternary swelling characteristics of the plastic to hard plastic residual, clay, silty clay slope and their thick about $2 \sim 8 \mathrm{~m}$, color is yellowish brown, yellow gray, grayish white. Due to the interaction of the rock soil characteristics and high temperature, rainy and humid climate conditions in the outer ring of Nanning, it often results in the embankment expansion shrinkage deformation and cutting slope cracking slump in the area of expansive soil.

\section{Expansive soil test}

\section{Basic soil test}

The exploration results show that the expansive soil of Nanning outer ring road is mainly distributed in the K6+000 K29+700 section of the peak forest farm to the five Tang town. In this paper, along with the engineering geological conditions along the highway, the author selects 3 representative sampling points to carry out the basic nature of the soil test, the test according to the requirements of JTG E40-2007 ${ }^{[8]}$, the test results are shown in table 1.

Table 1 Indicators of physical properties of the soil sample

\begin{tabular}{|c|c|c|c|c|c|c|c|c|c|c|c|c|c|}
\hline \multirow[b]{2}{*}{$\begin{array}{c}\text { Soil } \\
\text { sample } \\
\text { code }\end{array}$} & \multirow[b]{2}{*}{$\begin{array}{l}\text { Pile } \\
\text { No. }\end{array}$} & \multirow[b]{2}{*}{$\begin{array}{c}\text { Soil } \\
\text { depth } \\
\text { (m) }\end{array}$} & \multicolumn{5}{|c|}{ Physical properties } & \multicolumn{3}{|c|}{ Boundaries moisture content } & \multirow[b]{2}{*}{$\begin{array}{c}\text { Free } \\
\text { expansion } \\
\text { rate }(\%)\end{array}$} & \multirow[b]{2}{*}{$\begin{array}{c}\text { Standard } \\
\text { moisture } \\
\text { content } \\
\omega f \\
(\%)\end{array}$} & \multirow[b]{2}{*}{$\begin{array}{l}\text { Expansion } \\
\text { classification }\end{array}$} \\
\hline & & & $\begin{array}{c}\text { Natural } \\
\text { water } \\
\text { content } \omega \\
(\%)\end{array}$ & $\begin{array}{l}\text { Proportion } \\
\qquad G_{s}\end{array}$ & $\begin{array}{l}\text { Natural } \\
\text { Density } \\
\rho\left(\mathrm{g} / \mathrm{cm}^{3}\right)\end{array}$ & $\begin{array}{c}\text { Saturation } \\
S_{\mathrm{r}}(\%)\end{array}$ & $\begin{array}{c}\text { Void } \\
\text { ratio } \\
e\end{array}$ & $\begin{array}{c}\text { Liquid } \\
\text { Limit } \\
\omega_{\mathrm{L}}(\%)\end{array}$ & $\begin{array}{c}\text { Plastic } \\
\text { Limit } \\
\omega_{\mathrm{P}}(\%)\end{array}$ & $\begin{array}{c}\text { Plasticity } \\
\text { index } \\
I_{\mathrm{P}}\end{array}$ & & & \\
\hline 1\# & $\begin{array}{l}\mathrm{K} 21 \\
+650\end{array}$ & 1.5 & 21.0 & 2.77 & 1.93 & 79.0 & 0.737 & 56.4 & 24.1 & 32.3 & 45 & 4.4 & Weak \\
\hline $2 \#$ & $\begin{array}{c}\mathrm{K} 22 \\
+580\end{array}$ & 1.5 & 24.5 & 2.76 & 1.91 & 84.4 & 0.801 & 51.6 & 22.5 & 29.1 & 45 & 3.8 & Weak \\
\hline 3\# & $\begin{array}{r}\mathrm{K} 20 \\
+220\end{array}$ & 3 & 24.3 & 2.76 & 1.89 & 82.4 & 0.814 & 57.0 & 24.3 & 32.7 & 65 & 2.8 & Medium \\
\hline
\end{tabular}

From table 1 shows, the soil samples located about $1 \mathrm{~km}$, according to the actual measurement, the three soil free expansion rate for $45 \sim 65 \%$ and plastic index for $29.1 \sim 32.7$, standard moisture absorption water content rate between the 2.8 4.4. According to the current highway subgrade design specifications to determine the soil for the weak expansive soil.

\section{Mechanics and compaction, CBR test}

For the soil samples with quick shear test, heavy law compaction and CBR strength test, the results are shown in Table 2. 
Table 2 Results of mechanics, compaction and strength

\begin{tabular}{|c|c|c|c|c|c|c|c|c|c|c|c|}
\hline \multirow[b]{2}{*}{$\begin{array}{l}\text { Soil } \\
\text { sample } \\
\text { code }\end{array}$} & \multicolumn{2}{|c|}{ Mechanical test } & \multicolumn{2}{|c|}{ Compaction test } & \multicolumn{7}{|c|}{ CBR test } \\
\hline & $\begin{array}{l}\text { Cohesive } \\
\text { force }(\mathrm{kPa})\end{array}$ & $\begin{array}{l}\text { Internal } \\
\text { friction } \\
\operatorname{angle}\left({ }^{\circ}\right)\end{array}$ & $\begin{array}{l}\text { Optimum } \\
\text { moisture } \\
\text { content } \\
(\%)\end{array}$ & $\begin{array}{l}\text { Maximum } \\
\text { dry density } \\
\left(\mathrm{g} / \mathrm{cm}^{3}\right)\end{array}$ & $\begin{array}{l}\text { Compaction } \\
\text { number (hit / } \\
\text { layer) }\end{array}$ & $\begin{array}{l}\text { Compaction } \\
\text { moisture } \\
\text { content } \\
(\%)\end{array}$ & $\begin{array}{c}\text { Dry } \\
\text { density } \\
\left(\mathrm{g} / \mathrm{cm}^{3}\right)\end{array}$ & $\begin{array}{l}\text { Expansion } \\
\text { ratio (\%) }\end{array}$ & $\begin{array}{c}\text { Water } \\
\text { absorption } \\
(\mathrm{g})\end{array}$ & CBR2.5(\%) & CBR5.0(\%) \\
\hline $1 \#$ & 186.1 & 32.0 & 18.5 & 1.79 & 98 & 19.9 & 1.73 & 5.2 & 165 & 2.56 & 2.68 \\
\hline $2 \#$ & 67.2 & 27.8 & 16.0 & 1.82 & 98 & 18.1 & 1.83 & 4.3 & 138 & 2.67 & 2.81 \\
\hline $3 \#$ & 131.1 & 28.8 & 17.7 & 1.75 & 98 & 15.6 & 1.70 & 10.4 & 492 & 1.26 & 1.42 \\
\hline
\end{tabular}

According to the table 2, the fast shear tests of three kinds of soil samples show that the mechanical properties are good, and the strength is high; Heavy compaction test showed that the optimal moisture content of three soil samples was between 16.0 18.5\%, which has a difference about $2.5 \sim 8.5 \%$ of the natural moisture content showed in Table 1. As the conventional CBR test of three kinds of soil samples can not reach the requirement of less than $3 \%$. According to the current Highway Code, the soil cannot be directly used in the highway embankment filling, it must be treated before the use of the embankment.

\section{Expansion and contraction and swelling shrinkage ratio test}

Swelling and shrinkage test of expansive soil is required according to the JTGE40-2007[8] specification. For expansive soil swelling shrinkage rate test, because the current highway geotechnical testing procedures for JTGE40-2007 provide no corresponding testing methods, therefore, according to the highway subgrade design specification JTJ013-95[9] for the expansion and shrinkage total rate test, this article conducted the test and the test results are shown in table 3.

Table 3 Results of swelling-shrinkage properties

\begin{tabular}{|c|c|c|c|c|c|c|c|c|c|c|c|c|c|c|}
\hline \multirow[b]{2}{*}{$\begin{array}{c}\text { Soil } \\
\text { sample } \\
\text { code }\end{array}$} & \multicolumn{4}{|c|}{ Expansion test } & \multicolumn{3}{|c|}{ Shrinkage test } & \multicolumn{7}{|c|}{ JTJ013-95 Swelling shrinkage ratio } \\
\hline & $\begin{array}{c}\text { Free } \\
\text { expansion } \\
\text { rate } \\
(\%)\end{array}$ & $\begin{array}{c}\text { Expansion } \\
\text { force } \\
(\mathrm{kPa})\end{array}$ & $\begin{array}{c}\text { Okpa } \\
\text { Expansion } \\
\text { ratio } \\
(\%)\end{array}$ & $\begin{array}{c}50 \mathrm{kPa} \\
\text { Expansion } \\
\text { ratio }(\%)\end{array}$ & $\begin{array}{l}\text { Vertical } \\
\text { line } \\
\text { shrinkage } \\
(\%)\end{array}$ & $\begin{array}{c}\text { Body } \\
\text { shrinkage } \\
(\%)\end{array}$ & $\begin{array}{c}\text { Shrinkage } \\
\text { limit } \\
(\%)\end{array}$ & $\begin{array}{c}50 \mathrm{kPa} \\
\text { Expansion } \\
\text { ratio e } \mathrm{e}_{\mathrm{P} 50} \\
(\%)\end{array}$ & $\begin{array}{l}\text { Shrinkage } \\
\text { factor } \mathrm{c}_{\mathrm{s} 1}\end{array}$ & $\begin{array}{c}\text { Optimum } \\
\text { moisture } \\
\text { content } \\
\omega(\%)\end{array}$ & $\begin{array}{c}\text { Working } \\
\text { conditions } \\
\text { factor } \mathrm{K}\end{array}$ & $\begin{array}{c}\text { Plastic } \\
\text { Limit } \\
\omega_{\mathrm{P}} \\
(\%)\end{array}$ & $\begin{array}{c}\text { Shrinkage } \\
\text { moisture } \\
\text { content } \\
\omega_{\mathrm{m}}(\%)\end{array}$ & $\begin{array}{c}\text { Swelling } \\
\text { Shrinkag } \\
\text {-e ratio } \\
\mathrm{e}_{\mathrm{Ps}}(\%)\end{array}$ \\
\hline $1 \#$ & 45 & 268.7 & 10.1 & 3.83 & 1.4 & 4.9 & 16.0 & 3.83 & 0.312 & 18.5 & 0.873 & 24.1 & 21.0 & 3.83 \\
\hline $2 \#$ & 45 & 70.8 & 8.0 & 3.55 & 3.1 & 10.8 & 16.9 & 3.55 & 0.281 & 16.0 & 0.873 & 22.5 & 19.6 & 3.55 \\
\hline $3 \#$ & 65 & 79.1 & 11.9 & 7.30 & 1.0 & 4.7 & 19.3 & 7.30 & 0.123 & 17.7 & 0.873 & 24.3 & 21.2 & 7.30 \\
\hline
\end{tabular}

From table 3 we can see: No. 1 soil expansion force is the biggest, up to $268.7 \mathrm{kPa}$, other two kinds of soil samples of the expansive soil has little difference; expansion and shrinkage rate test showed that three types of soil are far greater than $0.7 \%$.

\section{Experimental study on chemical improvement of expansive soil}

\section{Standard for performance test of modified soil}

In order to analyze the various modified material effect on expansive soil improvement and adaptability, using lime, cement, and fly ash as an amendment, the three kinds of expansive soil selected above are studied in this research.

The effect of expansive soil improvement should make the expansive deformation and shrinkage deformation of compacted soil in the safety range, and at the same time, the filler should reach the corresponding strength requirements. As a result, the performance of the road with the improvement of the soil quality was tested by using the expansion shrinkage as the primary control index. According to the requirements of specifications for design of highway subgrades JTG E30-2004 ${ }^{[10]}$, the swelling shrinkage rate of the modified expansive soil should not exceed $0.7 \%$; As the CBR value is the strength of subgrade filler in the current standard, the test is still based on the CBR value as the strength of the modified soil testing index. The inspection requirements are as follows: the total rate of swelling shrinkage is less than or equal to $0.7 \%$; and CBR is not less than $3 \%$.

\section{Production of modified sample}

Using massive lime (calcium quicklime grade III and above) as the experiment lime, after grinding, through the $2 \mathrm{~mm}$ sieve and sealed for later use. According to the engineering experience in the past, 
the ash content accounted for dry soil mass ratio were $3 \%, 5 \%, 7 \%$; cement for 42.5 cement, admixture separately for 3\%, 5\%,7\%; fly ash (above two levels) incorporation were 15\%, 20\%, $30 \%$.

This test method was carried out by the test procedure of the highway engineering practice (JTGE40-2007) ${ }^{[8]}$ and the road engineering inorganic material. Quicklime and fly ash incorporated into soil material and mix well with it, according to the test to calculate the amount of water required, then sprayed on the mixture evenly and closed material one day after mixing thoroughly, and then made the sample preparation. Modified cement, the first we should be added the water to spray on the soil material evenly, and fully mix to homogeneity, then close the material one day. Adding the cement to soil material stuffy, stir evenly, then completed the sample preparation within one day. After the compaction and the isostatic compaction of soil improvement, we wrapped the soil samples using two layers of plastic, placed in a sealed box to keep moisture constant stand for seven days, and then started the test.

\section{Modified soil sample CBR test results}

Take the expansive soils to improve the test, in order to facilitate the analysis, the different lime, cement and fly ash incorporation and different amount of CBR and relationship between painting made a line chart (Figure 1), and the horizontal dashed line in Figure 1 corresponding to CBR value of $3 \%$.
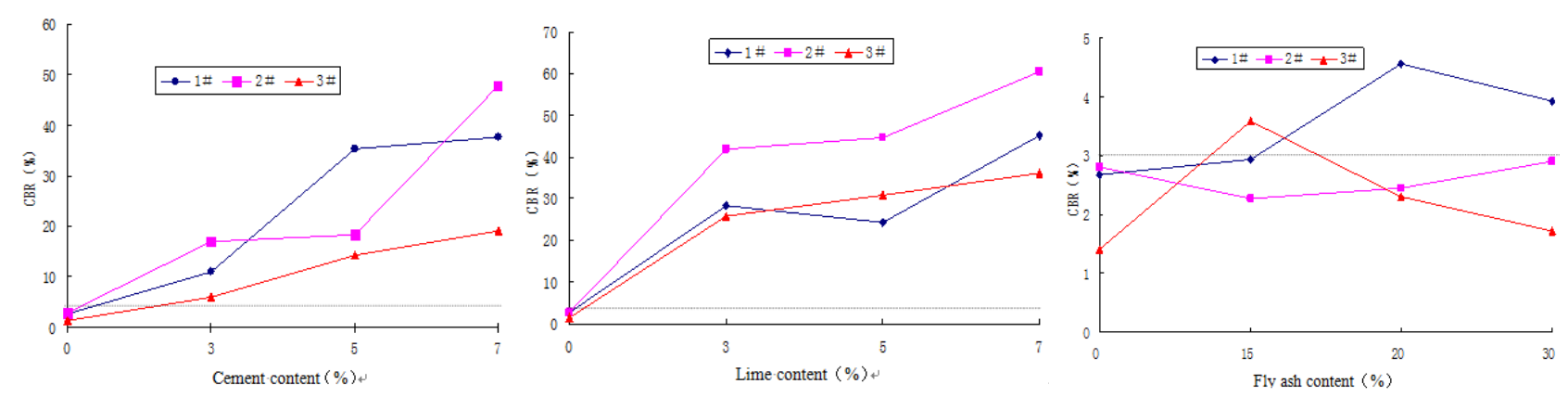

Fig.1 CBR value of different mixed with gray line

From the analysis of experimental results:

1. The CBR value of expansive soil mixed with cement increased greatly, and it increase significantly with the increase of cement content, the CBR value of different soil samples was more than $3 \%$;

2. The CBR value of expansive soil improved with lime increased greatly, and it increase significantly with the increase of lime content, the CBR value of different soil samples was more than $3 \%$;

3. The CBR value of expansive soil improved with fly ash also increase gradually. However, only the incorporation content of the No 1 soil sample was $20 \%$ and $30 \%$, the corresponding CBR value was more than $3 \%$, and it was more than $3 \%$ when the No. 3 soil's incorporation content is $15 \%$. Other CBR values are less than $3 \%$ of the specification requirements.

\section{Test results of improved soil samples}

According to the requirements of specifications for design of highway subgrades (JTG E30-2004) ${ }^{[10]}$, the swelling shrinkage rate of the modified expansive soil should not exceed $0.7 \%$. For expansive soil swelling shrinkage rate test, the current highway geotechnical testing procedures (JTGE40-2007) have no corresponding testing methods, this paper refers to (JTJ013-95) to carry out the experiment. Also in order to facilitate the analysis. The relationship between different amounts of lime, cement and fly ash and the rate of expansion and shrinkage was plotted.in Figure 2, and the overall rate of expansion of the horizontal lines in Figure 2 is $0.7 \%$. 

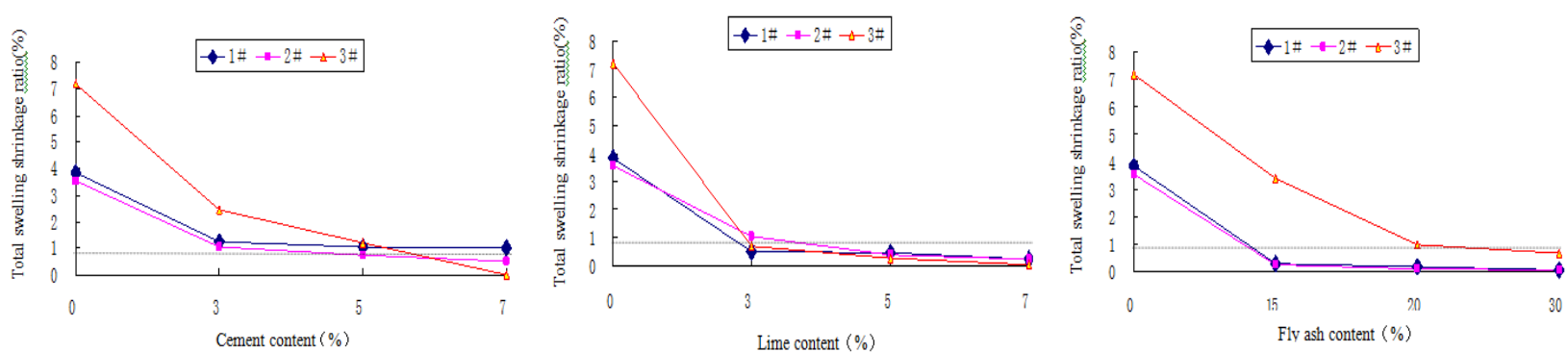

Fig. 2 Total rate of shrinkage and expansion of different mixed with gray line

From the analysis of experimental results:

1. The total swelling shrinkage ratio of expansive soil decreases a lot with the addition of cement and its value decreased more significantly with the increasing of the cement content. Only when the No. 2 and No. 3 soil sample doped with $7 \%$ of the cement can we achieve the requirements that total rate of swelling shrinkage is less than $0.7 \%$, and the other does not meet the requirements;

2. The total swelling shrinkage ratio of expansive soil decreases a lot with the addition of lime and its value decreased more significantly with the increasing of the lime content. In addition to the total swelling shrinkage ratio is more than $0.7 \%$ of No.2 soil sample with the content of $3 \%$, the other can meet the requirement of less than $0.7 \%$.

3. The incorporation of fly ash can effectively reduce the swelling shrinkage index, but No.3 soil samples with the incorporation of $15 \%$ and $20 \%$ cannot meet the requirements of the standard for the expansion and contraction of the total rate of less than $0.7 \%$.

\section{Improvement effect analysis}

For three different soil samples, the results of the modified expansive soil are summarized in table four, which are mixed by different content of lime, cement and fly ash. When the CBR value is less than $3 \%$ in the table with a red dashed line express, and blue italic for more than $0.7 \%$.

\begin{tabular}{|c|c|c|c|c|c|c|c|c|c|c|c|}
\hline \multirow{2}{*}{ Soil No. } & \multirow{2}{*}{ Project } & \multirow{2}{*}{ Plain soil } & \multicolumn{3}{|c|}{ Cement } & \multicolumn{3}{|c|}{ Lime } & \multicolumn{3}{|c|}{ Fly ash } \\
\hline & & & $3 \%$ & $5 \%$ & $7 \%$ & $3 \%$ & $5 \%$ & $7 \%$ & $15 \%$ & $20 \%$ & $30 \%$ \\
\hline \multirow{2}{*}{ 1\# } & CBR & $\underline{2.68}$ & 11.04 & 35.34 & 37.55 & 28.47 & 24.30 & 45.28 & $\underline{2.94}$ & 4.56 & 3.93 \\
\hline & swelling shrinkage ratio & 3.83 & 1.25 & 1.05 & 1.00 & 0.51 & 0.46 & 0.25 & 0.26 & 0.14 & 0.03 \\
\hline \multirow{2}{*}{ 2\# } & CBR & $\underline{2.81}$ & 16.93 & 18.41 & 47.85 & 41.96 & 44.54 & 60.37 & $\underline{2.28}$ & $\underline{2.45}$ & $\underline{2.90}$ \\
\hline & swelling shrinkage ratio & 3.55 & 1.05 & 0.73 & 0.50 & 1.05 & 0.37 & 0.25 & 0.25 & 0.06 & 0.05 \\
\hline \multirow{2}{*}{$3 \#$} & CBR & $\underline{1.42}$ & 5.89 & 14.27 & 19.14 & 25.77 & 30.92 & 36.07 & 3.58 & $\underline{2.31}$ & $\underline{1.72}$ \\
\hline & swelling shrinkage ratio & 7.20 & 2.43 & 1.20 & 0.01 & 0.68 & 0.26 & 0.05 & 3.40 & 0.96 & 0.66 \\
\hline
\end{tabular}

Analysis table four shows:

1. The CBR values of different amount of cement into the No. 1 soil samples were more than $3 \%$, which can meet the requirements, but cannot meet the specification of total rate of swelling shrinkage is less than $0.7 \%$; The CBR value of different amount of lime improved soil reached more than $3 \%$, and also to meet the expansion and shrinkage rate is less than $0.7 \%$;Fly ash content is $15 \%$, the CBR value of 2.94 , less than $3 \%$, which can meet the requirements, the incorporation of $20 \%$ and $30 \%$ can meet the requirements, also mixed with fly ash can meet the requirements of the specification of total rate of swelling shrinkage is less than $0.7 \%$. No.1 soil mixed with lime has the best improvement effect. When mixed with fly ash, only the content of the mixture is more than $20 \%$ can we get the good effect, and the improvement effect mixed with cement cannot meet the requirements.

2. The CBR values of different amount of cement into the No. 2 soil samples were more than $3 \%$, which can meet the requirements, but only the content up to $7 \%$ can it meet the requirements of total rate of swelling shrinkage is less than 0.7\%;The CBR value of the mixed lime is more than 3\%, which can meet the requirements, when the amount of lime content reached more than $5 \%$, it can meet the requirements of the expansion and shrinkage of the total rate of less than $0.7 \%$; The expansion and contraction rate mixed with fly ash could meet the requirements of less than $0.7 \%$, but CBR value are not up to the requirements of less than 3\%. For No. 2 soil, when the amount of 
lime to reach more than 5\% can achieve the improvement of requirements specification. Only when the cement content reach to $7 \%$ can it work, and mixing with the fly ash is not effective.

3. The CBR values of different amount of cement into the No. 3 soil samples were more than $3 \%$, but the content of $3 \%$ and $5 \%$ cannot meet the requirements of the standard for the expansion and contraction of the total rate of less than $0.7 \%$. The CBR values of mixed lime are more than $3 \%$, which can meet the requirements of the standard for the expansion and shrinkage of the total rate of less than $0.7 \%$. The CBR value and the swelling shrinkage ratio mixed with fly ash cannot meet the requirements at the same time, and the improvement effect is not good. For No. 3 soil, when the amount of lime to reach more than 3\% can achieve the improvement of requirements specification. Only when the cement content reach to $7 \%$ can it work, and mixing with the fly ash is not effective.

4. From the effect of various materials to improve the effect of the material, the effect of adding lime on the outer ring of Nanning is the best, and different soil samples with $5 \%$ 7\% content can meet the standard requirements. Improvement effect of cement of Nanning ring is not ideal, only No. 2 and No. 3 soil samples incorporation for $7 \%$ to meet highway specifications, others are not. The effect of adding fly ash is the worst, which does not meet the requirements.

\section{Conclusions}

1. According to the current standard, as the way of improving expansive soil, the double index test method which is based on the general rate of expansion and shrinkage is less than $0.7 \%$ and CBR value is more than $3 \%$ is reasonable.

2. With the increase of lime and cement content, improved soil CBR strength increase rapidly, when the amount of the two was reached 3\% and the CBR value was more than 3\%; The CBR strength of the modified soil mixed with fly ash is relatively slow, and the improvement effect is poor.

3. With the increase of the content of lime, cement and fly ash, the shrinkage and shrinkage rate of the modified soil decreases rapidly. When the cement content is 7\%, No.1 soil swelling shrinkage rate is greater than $0.7 \%$, but in the lime for more than $5 \%$, the total rate of swelling shrinkage of the three kinds of soil can meet requirements of less than $0.7 \%$.

4. From the improvement effect, the effect of lime improvement is the best in Nanning outer ring expansive soil, and when lime content of 5\%-7\% can meet the standard requirements. The improvement effect of cement on the outer ring of Nanning is relatively ideal, but for No. 2 and No. 3 soil samples, only when the cement content reaches $7 \%$ to meet the requirements. Ash doped Fen effect is the worst, do not meet the requirements.

\section{Acknowledgements}

This work was financially supported by the National Natural Science Foundation of China (No. 51009030)

\section{References:}

[1] Wang Bao-tian,Zhang Fu-hai. Improved technology and engineering of expansive soils [M].Beijing: Science Press, 2008.

[2] Guo Ai-guo,Kong Ling-wei,Hu Ming-jian,etc. On Determination of Optimum Water Content of Lime-Treated Expansive Soil [J]. Rock and Soil Mechanics,2007,28(3):517 521.

[3] MADHYANNAPU R S, PUPPALA A J, NAZARIAN S,et al. Quality Assessment and Quality Control of Deep Soil Mixing Construction for Stabilizing Expansive Subsoils[J].Journal of Geotechnical and Geoenvironmental Engineering,2010,136(1): 119 128.

[4] LI Xin-wei,Wang Xiao-fei,Feng Zhong-ju. Test and Study on Modified Effect of Expansive Soil in Xi'erhuan Expressway of Guangzhou City [J]. HIGHWAY,2010(10):104-106.

[5] HUANG Bin,Nie Qiong, Xu Yan-yong,etc. Experimental Research on Cement-modification of Expansive Soil [J]. Journal of Yangtze River Scientific Research Institute.2009.26(11):27-30.

[6] CAI Y,SHI B, NG C W W,et al. Effect of Polypropylene Fiber and Lime Admixture on Engineering Properties of Clayey Soil [J]. Engineering Geology,2006,87(3-4):230-240.

[7] KUMAR A,WALIA B S, BAJAJ A. Influence of Fly Ash,Lime,and Polyester Fibers on 
Compaction and Strength Properties of Expansive Soil[J]. Journal of Materials in Civil Engineering,2007,19(3): 242-248.

[8] Industry Standard of the People's Republic of China. Code for Design of Highway Subgrade (JTG D30-2004).Beijing.

[9] Industry Standard of the People's Republic of China. Code for Highway Geotechnical Testing (JTG E40-2007). Beijing.

[10] Industry Standard of the People's Republic of China. Code for Design of Highway Subgrade (JTJ013-95). Beijing. 